\title{
Theoretical and Methodological Approaches to Ecological Changes, Social Behaviour and Human Intergroup Tolerance 300,000 to $30,000 \mathrm{BP}$
}

\author{
Penny Spikins $^{1}$ (D) Jennifer C. French ${ }^{2} \cdot$ Seren John-Wood ${ }^{3,4} \cdot$ Calvin Dytham $^{5}$
}

Accepted: 15 December 2020 / Published online: 3 February 2021

(C) The Author(s) 2021

\begin{abstract}
Archaeological evidence suggests that important shifts were taking place in the character of human social behaviours 300,000 to 30,000 years ago. New artefact types appear and are disseminated with greater frequency. Transfers of both raw materials and finished artefacts take place over increasing distances, implying larger scales of regional mobility and more frequent and friendlier interactions between different communities. Whilst these changes occur during a period of increasing environmental variability, the relationship between ecological changes and transformations in social behaviours is elusive. Here, we explore a possible theoretical approach and methodology for understanding how ecological contexts can influence selection pressures acting on intergroup social behaviours. We focus on the relative advantages and disadvantages of intergroup tolerance in different ecological contexts using agent-based modelling $(\mathrm{ABM})$. We assess the relative costs and benefits of different 'tolerance' levels in between-group interactions on survival and resource exploitation in different environments. The results enable us to infer a potential relationship between ecological changes and proposed changes in between-group behavioural dynamics. We conclude that increasingly harsh environments may have driven changes in hormonal and emotional responses in humans leading to increasing intergroup tolerance, i.e. transformations in social behaviour associated with 'self-domestication'. We argue that changes in intergroup tolerance is a more parsimonious explanation for the emergence of what has been seen as 'modern human behaviour' than changes in hard aspects of cognition or other factors such as cognitive adaptability or population size.
\end{abstract}

Keywords Modern human behaviour . Tolerance $\cdot$ Social connectivity $\cdot$ Agent-based model $\cdot$ Environmental change $\cdot$ Palaeolithic $\cdot$ Self-domestication

Guest editors: Anders Högberg and Marlize Lombard

Penny Spikins

penny.spikins@york.ac.uk

Extended author information available on the last page of the article 


\section{Introduction-Approaches to the 'Modern Human Transition'}

Of all the key transitions in human evolution it is that which occurred between 300,000 and 30,000 years ago - the 'modern human transition'- which is the focus of the most intense debate (Högberg and Lombard, this volume). It is during this period that we see the emergence of our own species Homo sapiens, otherwise referred to as anatomically and cognitively modern humans (ACMH).

Whilst there remains a consensus that after 300,000 years ago, and following the spread of modern humans out of Africa, the range and frequency of key elements of 'modernity' increase (French 2018), the broader mechanisms by which new biological forms of hominin and new types of technological and social behaviour emerge remain poorly understood (d'Errico and Banks 2013; Moncel and Schreve 2016). Modern human behaviour (defined as behaviours that indicate modern-level linguistic and cognitive abilities and identified archaeologically through the presence of, among others, deliberate burials, complex lithic and hafting technologies, personal ornamentation, pigment use and 'symbolic' art and artefacts; Henshilwood and Marean 2003; Mellars 2007) is far from unproblematic as a concept (Ames et al. 2013), and many elements of such behaviour were also exhibited by archaic humans (e.g. Zilhão et al. 2010; Joordens et al. 2015; Hoffmann et al. 2018; Kissel and Fuentes 2018). Furthermore, prosocial motivations and behaviours, including care for the ill and injured (Spikins et al. 2019), and collaborative hunting practices and food sharing (Domínguez-Rodrigo et al. 2014; Agam and Barkai 2016; Faurby et al. 2020), emerged relatively early in human evolution. Nonetheless, it is largely after 300,000 years ago that many complex social and cultural behaviours became widespread.

Certain particularly interesting patterns of change are evident in human social behaviours in Africa 300,000-30,000 years ago. Alongside increased ecological variability in East Africa around 300,000 BP, we see evidence of increased raw material transfer distances (Potts et al. 2018), indicating changes in patterns of group and intergroup mobility. From typically local raw material transfer distances of around $5 \mathrm{~km}$, we see new movements of obsidian of around 25 to $50 \mathrm{~km}$ - and up to $95 \mathrm{~km}$ in certain cases-implying interactions with neighbouring groups (Brooks et al. 2018). Middle Stone Age populations in the Kalahari also imported preferred silcrete raw material from up to $295 \mathrm{~km}$, particularly during drier periods (Nash et al. 2013, 2016), well beyond the transfer distances typically recorded in previous periods. Greater patterns of large-scale regional mobility both within Africa and beyond are also evident from genetic data (Timmermann and Friedrich 2016; Lamb et al. 2018; Petraglia et al. 2019; Rito et al. 2019).

Important anatomical changes associated with the emergence of anatomically modern humans also occurred during the same period, with so-called craniofacial 'feminisation' drawing the most attention (Cieri et al. 2014). From around 300,000 years ago, certain populations in Africa display traits such as a reduction in brow ridges and other changes in facial form, as well as increased gracility associated with anatomically modern humans (Stringer and Galway-Witham 2017), with populations at Jebel Irhoud in Morocco dating to around 315,000 years ago being a particularly notable example (Hublin et al. 2017; Richter et al. 2017). Whilst archaic forms continued to be represented, crania such as that from Omo 1, dated to around 195,000 years ago or Herto, dated to 165,000-100,000 years ago are considered modern 
in appearance (Klein 2019). This was a period of both marked behavioural change and marked physiological and anatomical change.

These archaeological and anatomical changes were set against a backdrop of marked ecological challenges. Across the whole continent, the expansion and contraction of the Sahara basin structure and variable topography provided a unique environment (Foley 2018) in which distinct subdivided populations seem to have emerged and periodically connected (Scerri et al. 2018; Galway-Witham et al. 2019). Both southern and eastern Africa were key to the emergence of modern humans (Rito et al. 2019). Increasing aridification from half a million years ago in East Africa placed particular pressures on the survival of many mammalian species and is associated with mammalian extinctions between 500 and 400,000 years ago (Owen et al. 2018). Alternating periods of arid and wetter conditions also affected southern African environments, placing particular pressures on human populations in arid periods and prompting dispersions along wetter corridors (Simon et al. 2015; Kutzbach et al. 2020). Whilst the precise conditions under which our species emerged remain unclear and much debated, distinctively spatially and chronologically variable — and often increasingly resource poor — environments appear to have been key to the complex patterns of evolutionary change taking place within both archaic and modern humans.

The mechanisms by which these ecological changes might lead to such notable changes in anatomy, physiological and behaviour remain to be explored. A particular challenge lies in understanding the relationship between biological/anatomical and/or social/cognitive change, and how these relate to ecological context. All too often traditional disciplinary boundaries, alongside preconceptions about how evolutionary processes ought to work, further a distinction between changes in body (biological/ anatomical change) assumed to be driven by ecological changes and changes in mind (social/cognitive change) assumed to be driven by internal social processes (Fig. 1).

\section{Ecological Changes and Selection Pressures on Social Tolerance}

An understanding of how ecological contexts influence changes in social-emotional dispositions may provide a pathway to link ecological-biological and social-cognitive approaches and contribute additional insights into the nature of key transformations occurring 300,000-30,000 years ago.

Evolutionary transformations in emotional dispositions and responses are likely to have played an important role in key transitions in human evolution (Decety et al. 2012; Spikins et al. 2019; Marsh 2019; Spikins 2021). Variations in oxytocin responses, for example, have a notable influence on caring behaviours in modern human populations (Marsh 2019), undergo significant changes in human evolution (Theofanopoulou et al. 2018) and are implicated in food sharing (Wittig et al. 2014), care for injured adults (Spikins et al. 2019) and teaching and learning in other species (Thornton and McAuliffe 2006). The transition into a new human niche involving greater levels of carnivory from around two million years ago (Domínguez-Rodrigo et al. 2014) is likely to have involved changes in collaborative emotional dispositions, including those affected by oxytocin, that facilitated food sharing, shared infant care and care for vulnerable and injured adults, much as is seen among social carnivores. 


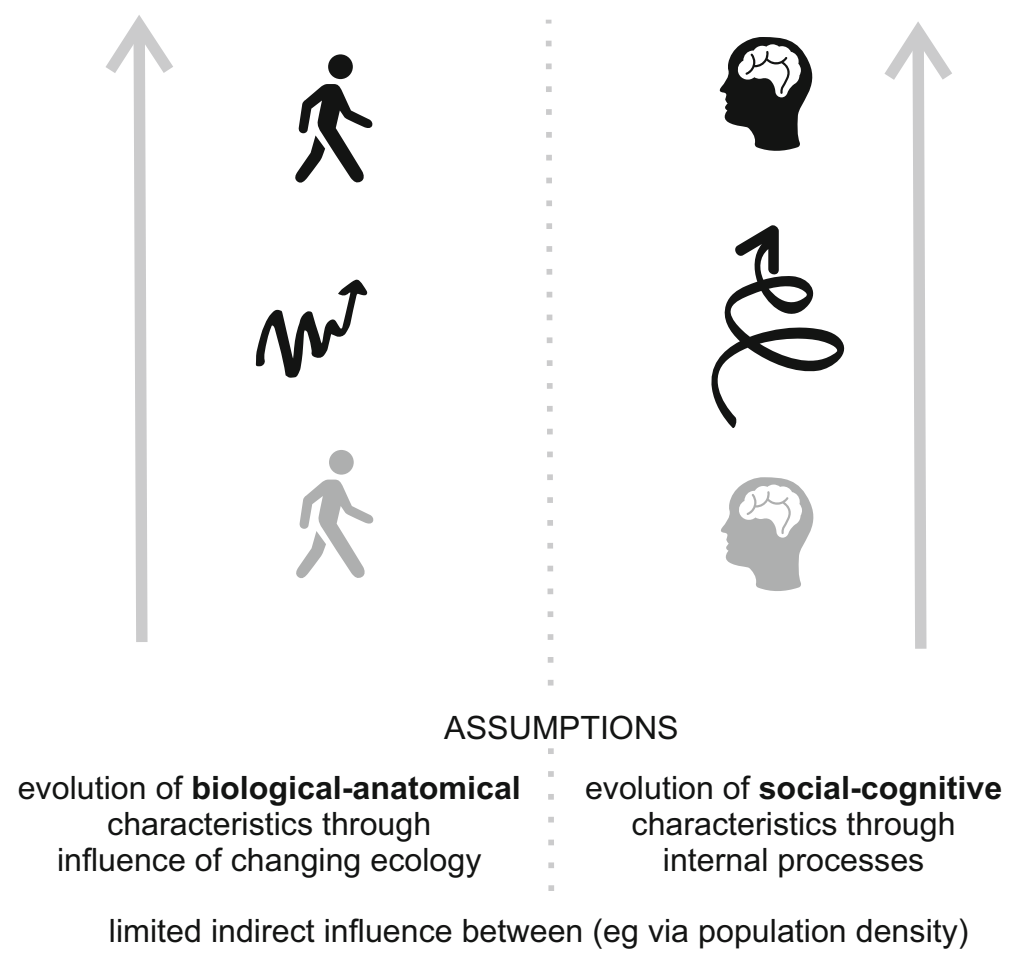

Fig. 1 Simplified graphical illustration of commonly assumed distinctions and relationships between evolutionary processes affecting the evolution of the human mind and body as separate processes affected by differing influences. Left: representation of assumed evolution of body shape through interactions with the environment, right: representation of assumed evolution of mind through internal social processes

Emotional dispositions also play a key role in social connectivity at a regional scale. Emotional reactions to 'outsiders' are influenced by hormonal responses affecting approach behaviours (i.e. friendliness) through hormonal influences on fight or flight responses (affected by hormones such as cortisol) and willingness to explore (affected by hormones such as dopamine; Wilkins et al. 2014). Key changes in these hormone systems occurred over the last 300,000 years (Theofanopoulou et al. 2017) and have also been implicated in the evolution of fully modern language (Thomas and Kirby 2018). Whilst it would be foolish to suggest that anything as complex as human regional social interactions is just about biology, the influence and constraints of emotional responses play an important role even in modern contexts (Sapolsky 2017).

\section{Ecological Selection Pressures on Intergroup Tolerance}

The relationship between ecological changes and selection pressures on intergroup tolerance may have played a significant role in the changes in social connectivity and mobility that occurred 300,000-30,000 years ago. The relationship between ecology, resource distributions and intergroup tolerance in mammals in general, and in primates specifically, provide useful insights.

Even though unfamiliar individuals are typically a threat to territories or resources, there are several factors which can promote rather than constrain tolerance towards 
unfamiliar or 'outgroup' individuals. The most obvious and important factor is access to resources. Tolerance enables exploitation of resources at boundaries whilst avoidance or aggression makes such exploitation impossible. The friendly interaction at boundaries recorded in bonobos (Pan paniscus) facilitates exploitation of boundary resources such as fruiting trees as well as small prey, for example (Tan and Hare 2013; Tan et al. 2017; Hare and Yamamoto 2017; Lucchesi et al. 2020). Bonobos from different groups will willingly share food with non-group members and have been observed actively sharing with other groups at boundaries (Tan et al. 2017). In ecological contexts, where resources are highly clustered and critical for survival, tolerance may be particularly key to enabling access (Pisor and Surbeck 2019).

The advantages which tolerance may bring to resource exploitation is not the only factor promoting tolerant intergroup interactions. Other factors include the following: the potential for gathering information before the transfer of individuals within mating networks; increased opportunities for extra group meeting and collaborative defence (Pisor and Surbeck 2019). Collaboration between unrelated colonies has even been recorded in eusocial ants as a means of collaborative predator defence (Robinson and Barker 2017). Clearly, ecological changes affecting resource availability and the distribution of resources, as well as other factors such as predation will influence selection pressures on tolerant, rather than avoidant, or aggressive, reactions to 'outsiders' (Fig. 2).

Archaic humans would have been particularly vulnerable to these changes due to their dependence on several types of resources; not only plant and animal foods but also raw materials for tool manufacture and other resources such as medicines (Hardy 2018). Modern ethnographically documented hunting and gathering populations demonstrate a high degree of intergroup interactions (Bird et al. 2019) and dependence on intergroup transfers (Pisor and Surbeck 2019). Intergroup collaboration allows access to widely distributed resources, such as salt, medicines and raw materials for toolmaking (Pisor and Surbeck 2019) and buffers against resource unpredictability and shortfalls (Wiessner 2002; Dyble et al. 2016). The Ju'hoansi 'hxaro' network-a system of

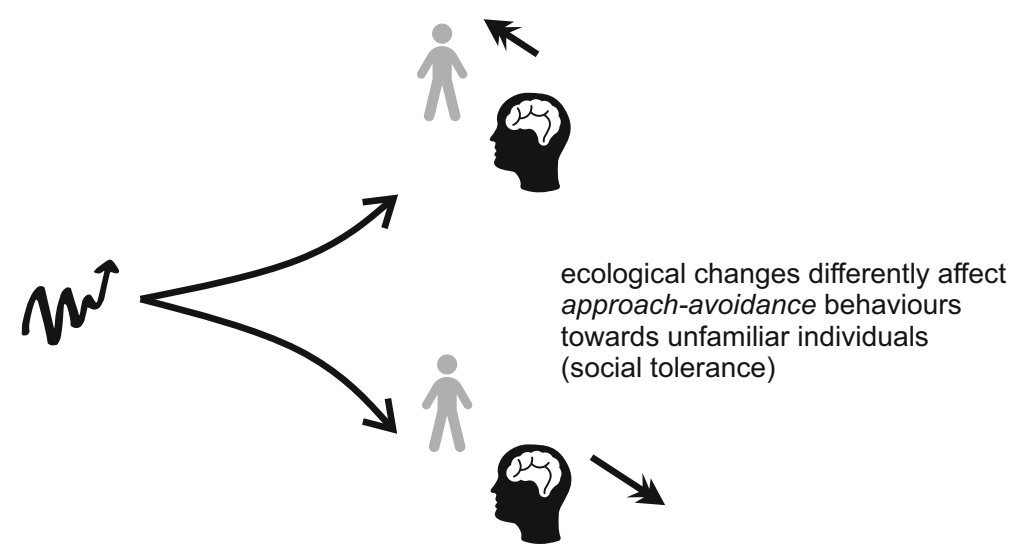

Fig. 2 Graphical illustration of how ecological changes affect tendencies to approach-avoidance behaviours towards unfamiliar individuals through evolved hormonal responses affecting social tolerance. Ecological changes (left) can have different evolutionary effects on brain and physiology from promoting more tolerant behaviours (upper right) to promoting less tolerant behaviours (lower right) 
distant allies able to provide support in times of resource shortfall - is perhaps the bestknown ethnographic example of how intergroup tolerance and collaboration foster survival (Wiessner 2002). Many other examples also exist. In Tierra del Fuego, beached whales are exploited by different communities who reciprocate the opportunity by alerting others and allowing entry into their territory (Santos et al. 2015).

Attention has focused on the significance of multilevel networks in human evolution (Grove et al. 2012; Layton et al. 2012). However, a focus on changes in social tolerance between foraging or kin groups may be a more useful theoretical approach, particularly given that evidence for high levels of inbreeding (discussed below) is difficult to reconcile with what we know of multilevel networks. Whilst we have assumed that the evolutionary origins of regional networks of connectivity lie predominantly in an increasingly complex cognition, physiological changes influencing social behaviour may have played a far more significant role than has previously been considered.

\section{Intergroup Tolerance in Archaic Humans}

There was almost certainly some level of regional population connectivity among archaic humans (e.g. Greenbaum et al. 2019), although evidence suggests that this social connectivity was subject to notable constraints. For example, evidence from skeletal abnormalities (Ríos et al. 2015, 2019; Trinkaus 2018) and genetics (e.g. Castellano et al. 2014) suggest high rates of inbreeding throughout the Lower and Middle Palaeolithic which would be unlikely to have occurred where social groups were fluid and connected. Across the archaic world, there were limited connections beyond home ranges until at least 500,000 years ago (Marwick 2003; Layton et al. 2012). In Eurasia, the long genetic history of close interbreeding (equivalent to the halfsibling level) seen in the genome of the Altai Neanderthal (Prüfer et al. 2014), contrasts with the evidence for the ACMH Sunghir burials II, III and IV, whose genome sequences indicate exogamous mating practices (Sikora et al. 2017). Nonetheless, connections of some kind over long distances existed. In Middle Palaeolithic Europe, there are rare examples of long distance material movements (Féblot-Augustins 1999), and even rarer examples of distant raw materials predominating where local materials are unsuitable as reported by Spinapolice (2012) in southern Italy. However, as a whole, there is little evidence for frequent social interaction between groups. The evidence for longer distance movements outside of a group's typical range is consistent with what we might expect when external social connections were uncommon (Djindjian 2012), perhaps limited to movements around mating patterns (which may have been constrained by patrilocality; see Lalueza-Fox et al. 2011).

Even what we might consider as the first stage of regional intergroup connectivityresource exploitation at boundaries - is not always evident. In the Middle Palaeolithic of the Levant, detailed studies of the transport of flint materials to the site of 'Ein Qashish' even suggest potential borders between groups where resources remained unexploited (Ekshtain et al. 2014, 2017; Hovers 2018). We can reasonably assume that archaic groups were capable of the kind of intergroup or landscape scale interactions recorded in bonobos (i.e. exploitation of resources between groups and some sharing of resources), not only on the basis of common ancestry but also on the basis of evidence from raw material transfers. However, the level of social tolerance which we often 
assume characterised human societies for much of our evolutionary past - frequent social connection and access to complementary resources as well as mating opportunities - is far more elusive than we might expect.

There is little doubt that transformations in connectivity 300,000-30,000 years ago significantly changed regional social relationships, laying the basis for fluid social and biological connections to emerge, as well as regular aggregations, and the spread of new innovations and ways of doing things (Gamble 2009; Coward 2015; French 2016, 2018). Physiological changes in response to the influence of changing ecology on selection pressures towards intergroup social tolerance are likely to have played a key role in these transformations. Whether 'self-domestication' is an appropriate term to apply to changes in the human evolutionary past or not remains debated (see SánchezVillagra and van Schaik 2019). Nonetheless, it is clear that between 300,000 and 30,000 years ago, there were transformations in physiology and anatomy in emerging modern human populations associated with changes in hormone function and which are broadly associated with increased tolerance (Theofanopoulou et al. 2017). Analogies have been drawn between the changes observed in humans and those seen in other primates (such as distinctions between common chimpanzees and bonobos) and other species less closely related to humans (such as wolves and free ranging dogs).

Here, we investigate the mechanisms behind these changes in social disposition which are often generalised within the term 'self-domestication'. To illustrate potential methods to better understand such changes, we develop an agent-based model (ABM) to simulate the potential effects of ecological changes on intergroup tolerance in archaic humans. We simplify two different populations within the broad classification as being 'avoidant' and 'tolerant' in order to compare these different strategies in differing ecological contexts.

\section{Method}

\section{Model Overview}

We use a spatially explicit, agent-based model to simulate individuals attached to groups (or 'bands' within modern ethnographic contexts; Hill et al. 2014) of hunter-gatherers. Agent-based models are a widely used tool for investigating complex systems (Railsback and Grimm 2019). They have long been used in archaeology to reveal how individuals interact with each other and their environment to produce emergent patterns (reviewed by Premo 2006; Cegielski and Rogers 2016; Romanowska et al. 2019). It has been shown that prey depletion across a landscape with interacting individuals is best addressed using a simulation model (Křivan and Eisner 2003). Brantingham (2003) used a model of individuals moving around a spatially heterogeneous landscape encountering, collecting and processing resources to provide a null model of the diversity of stone sources that would be found in a toolkit.

Here, we model individual humans moving around a dynamic landscape hunting resources (similar to Janssen and Hill 2014, but with more abstract animal populations). Our focus is on the effect of the nature of intergroup interactions, and whether food resources are shared when groups meet. Individuals foray from their group foci to acquire resources and to interact with other groups, and they also age and may reproduce. The model is implemented in C\# and compiled and run on a PC using Microsoft Visual Studio 2019. 
Like every model, this simulation cannot represent the full extent of all social interactions among archaic humans; therefore, it simplifies some of these aspects to allow us to explore key questions. We use a series of assumptions based on a simplification of what is known about the social behaviour of archaic humans:

- We assume that archaic humans belong to groups distributed across a landscape, and that these groups can move around and interact with other groups

- Groups may interact, with the probability of interactions higher when group foci are closer (i.e. that each group is not seeking each other out but interacting randomly)

- Social interactions may be 'avoidant' or 'tolerant', with the latter allowing for potential transfers of resources from a group with excess resources to one with a deficit (resource sharing)

- Resources (in this case hunted food, though foraged plant foods would function in the same way) are tracked in landscape cells. Food is needed for maintenance and excess food is needed for successful reproduction

- Animal populations increase following logistic growth and successful hunting removes animals from the landscape and adds food to a group's supply

- Individuals age and suffer age-dependent mortality, and mature females can reproduce (when the group has sufficient resources)

Our use of 'tolerance' in this context implies a positive interaction with members of other groups, leading to the possibility of resource transfers to those in need from those with available resources, in accordance with sharing as observed in modern ethnographically documented contexts (Lavi and Friesem 2019; Spikins 2019).

\section{Model Operation}

\section{Initialisation}

At initialisation there are 160 group foci placed randomly in continuous space within the landscape. The starting population of humans is 3000 individuals randomly assigned to a group and starting at the group focus. Individuals have a random age ( 1 to 50) and sex (even chance) assigned at the start of the simulation. Animal populations are set independently for each grid cell and initially have a random value (1 to 100).

\section{Model Flow}

There are several phases within a model year. Further details of these phases are given in the Supplementary Materials.

Hunting Individuals each start from their group focus point and, if old enough to hunt, take a series of step moves with hunting attempted at the end of each step. A successful hunt adds a unit of resource to the group's stock.

Intergroup Interactions Pairs of groups are selected at random and may meet for an intergroup interaction where, if tolerant, resources may be exchanged. 
Maintenance Individuals eat food from the group's supply for subsistence.

Ageing, Birth and Death All individuals age each year and there is an age-specific probability of death. Adult females in groups with excess resources may have offspring.

Group Fission and Loss Groups of size 50 and above split, those below size 4 are lost.

Animal Population Growth See Supplementary Materials.

\section{Elements and Variables of the Model}

The elements and variables used in the model are described in Table 1.

\section{Model Realisations}

For each model realisation here, we focus on the total population size as a measure of success. In all simulations, the population size reported is the mean total population within a realisation between timesteps 901 and 1000 .

Populations within a simulation are either 'avoidant' where there are no intergroup interactions (other than indirectly through exploitation competition) or 'tolerant' where positive intergroup interactions (food sharing) are possible. We vary the 'harshness' of the environment by changing the cost of offspring from 26 (benign) to 35 (harsh). There are 200 replicate simulations of each tolerance/environment combination.

We then repeated the simulations with temporal environmental heterogeneity. This was achieved by adding variation in the cost of reproduction between years to simulate a mix of good and bad years with the same mean. Each year we added a value to the cost of reproduction value drawn as a random uniform integer ( -7 to 7$)$, mean 0 , standard deviation of 4.7. Variation was added independently each year and there was no temporal autocorrelation.

An illustration of the model in operation is shown in Fig. 3.

\section{Results}

The model outputs allow us to make observations about the advantages or disadvantages of strategies of tolerance or avoidance of other groups under different environmental conditions.

Unsurprisingly, the harshness of the environment has a notable effect on the population size (Fig. 4), with harsher environments supporting smaller populations. Intriguingly, this effect is much more pronounced for avoidant than tolerant strategies - sharing food resources across borders is advantageous, leading to higher population density and greater probability of survival. Sharing can still be costly nonetheless, and interestingly the benefits of sharing become less evident in the harshest environments as the costs of sharing become more significant in relation to resources required for immediate survival. 
Table 1 Explanation of elements and variables used in the model

\begin{tabular}{ll} 
Element & Explanation \\
\hline Landscape & The landscape is represented by a regular grid of $100 \times 100$ landscape cells \\
& (the side length referred to as a 'grid unit'). Each landscape cell supports an \\
independent animal population. \\
An individual human located in continuous space within the landscape. An \\
individual's sex, age and group affiliation is tracked. \\
Individual \\
located in continuous space, that remains fixed for a season. Groups are \\
assumed to pool hunted resources and successful hunting adds to the \\
group's stock. \\
All individuals older than 10 are assumed to move in forays through the \\
landscape and hunt resources (detailed description in supplementary \\
materials and see flowchart in supplementary section).
\end{tabular}

Maintenance and starvation Each group loses 1 unit of food for each group member to provide subsistence. If there is insufficient food to cover this maintenance, individuals may starve (detailed description in supplementary materials).

Birth and death

Females between ages 16 and 39 have offspring if there is sufficient food after maintenance to cover the birth cost. There is age-dependent death applied following (Gurven and Kaplan 2007; Hill et al. 2007; Kelly 2013) in addition to death from starvation.

Group loss and group fission Any group with fewer than four members is dissolved, and all remaining group members are assumed to have died. Any group with 50 or more members will split into two. At group fission, all individuals in the current group are randomly assigned to one of the two daughter groups. One group will have its focus in a new location (details in supplementary materials).

Animal population growth

Each landscape grid square has an independent animal population and the end of each year, populations can increase following logistic growth (details in supplementary materials).

'Harshness' of environment Harshness of the environment is varied by varying the cost of births. Here we use a range of costs of reproduction from 26 to 35 .

Tolerance (potential for resource transfer)

Within a simulation run, all groups are either 'avoidant' or 'tolerant'. If groups avoid each other, no food will be transferred, and when groups are tolerant, food will be transferred (shared) if one has a surplus and the other a deficit.

Storage of resources

There is no long-term storage of resources and groups start each hunting season with no stored food.

The relative probability of populations surviving or failing to secure enough resources for survival under different strategies of avoidance or tolerance to other groups also shows interesting patterns. In benign environments, all populations persist, but again, unsurprisingly, harsh environments (where reproduction is costly) reduce population survival (Fig. 5). However, interestingly, tolerant populations (which are able to share resources) are less affected by increasingly harsh environments - a tolerant population not only has a higher population size than an avoidant population (Fig. 4) but also a tolerant population is more likely to survive in a harsh environment, and therefore less likely to become locally extinct (i.e. where a total population falls to zero) (Fig. 5).

Statistical analysis supports these observations. A two-way ANOVA with population size as the response variable and tolerance and cost of reproduction as predictors shows strongly significant effects of both factors. There is also a highly significant 


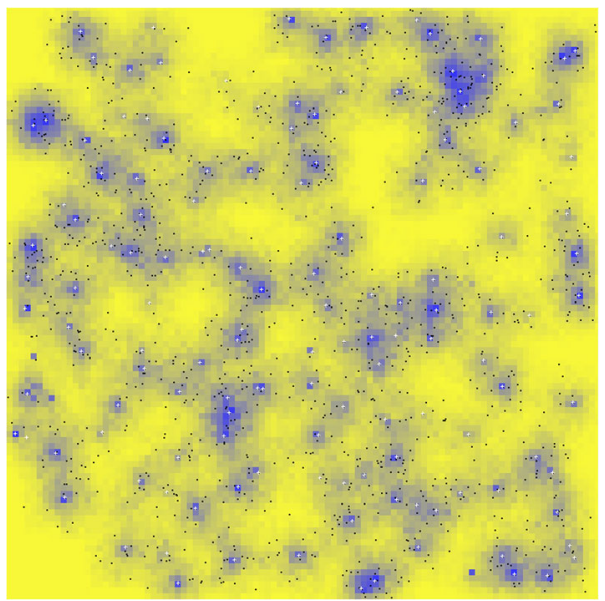

Fig. 3 A snapshot of the model in action. Blue dots are individual foragers, and white crosses are group foci or 'camps'. Dark blue to yellow shading in landscape cells indicates the level of available resource from low to high. The effect of depletion of resources near camps is clear

interaction between predictor factors. Effect sizes, as measured by $\eta^{2}$, for the main effects are 0.94 for cost of reproduction, 0.27 for tolerance and 0.01 for their interaction, with all $p$ values $<0.001$, although significance levels for simulation models should be treated with some caution (White et al. 2014). To investigate the form of the interaction between tolerance and cost of reproduction (environmental harshness), we expressed the results as tolerant population size/avoidant population size. Tolerance (food sharing) has a positive effect (ratio $>1$ ) throughout, but the scale of the effect varies with environmental harshness.

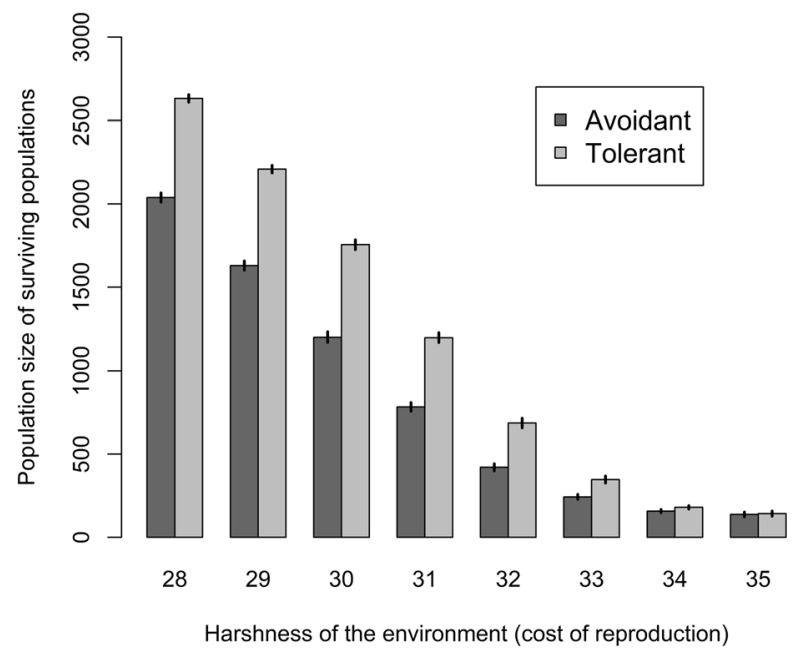

Fig. 4 A range of costs of reproduction with avoidant (dark tone, left column) and tolerant (light tone, right column) simulations. Data shown are the mean population size at the end of the simulation from up to 200 replicates for each bar (fewer in more harsh environments where there are extinctions). Error bars show $95 \%$ confidence intervals 


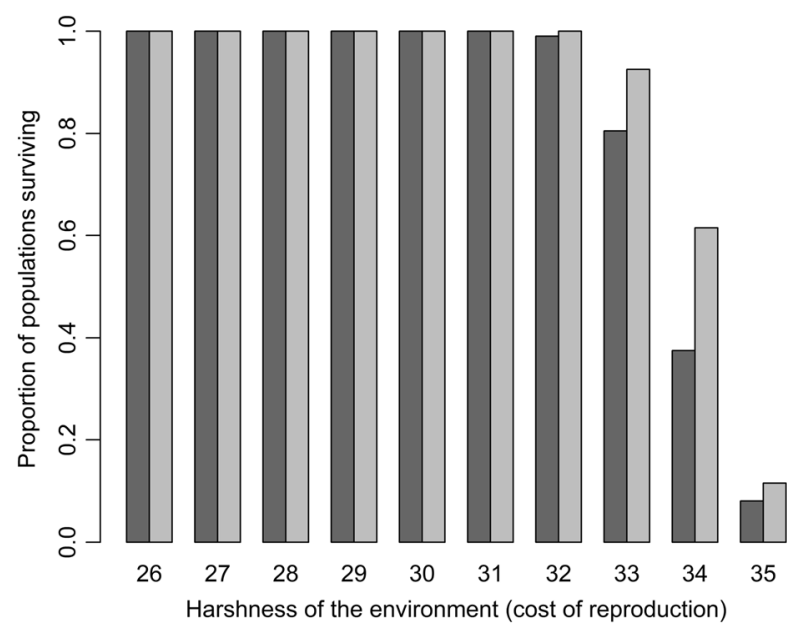

Fig. 5 Proportion of simulations with population over zero at the end (i.e. survival). Two hundred simulations for each bar with avoidant (dark grey) and tolerant (light grey) simulations

As we see from Fig. 6, whilst tolerance is a generally advantageous strategy, this advantage is most pronounced where environments are neither extremely benign (where sharing becomes less necessary for reproduction and survival) nor extremely harsh (as the costs of sharing become more significant in relation to the resources needed to reproduce and survive).

Figure 7 shows the effect of adding environmental variability through interannual variability in cost of reproduction. It confirms the pattern in Fig. 6, indicating a clear

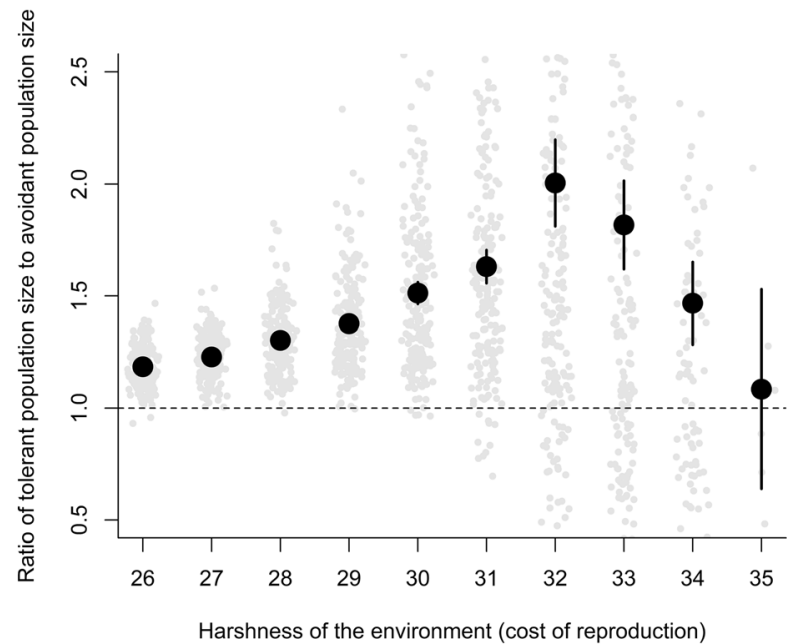

Fig. 6 Population size of tolerant simulations/avoidant simulations, means are filled black circles. A value of 1 (shown with a dashed horizontal line) will result if there is no effect of resource sharing, values over 1 indicate tolerant populations are larger, a value of 1.5 showing $50 \%$ larger. Two hundred pairs of simulations (1 avoidant, 1 tolerant) were run for each level of environmental harshness, and raw data for the ratio in each pair are shown in light grey circles. Ratios are only available when both populations in the pair of simulations persisted to the end of the simulation. 95\% confidence intervals are shown (note that for low values of environmental harshness, these are within the circle showing the mean) 


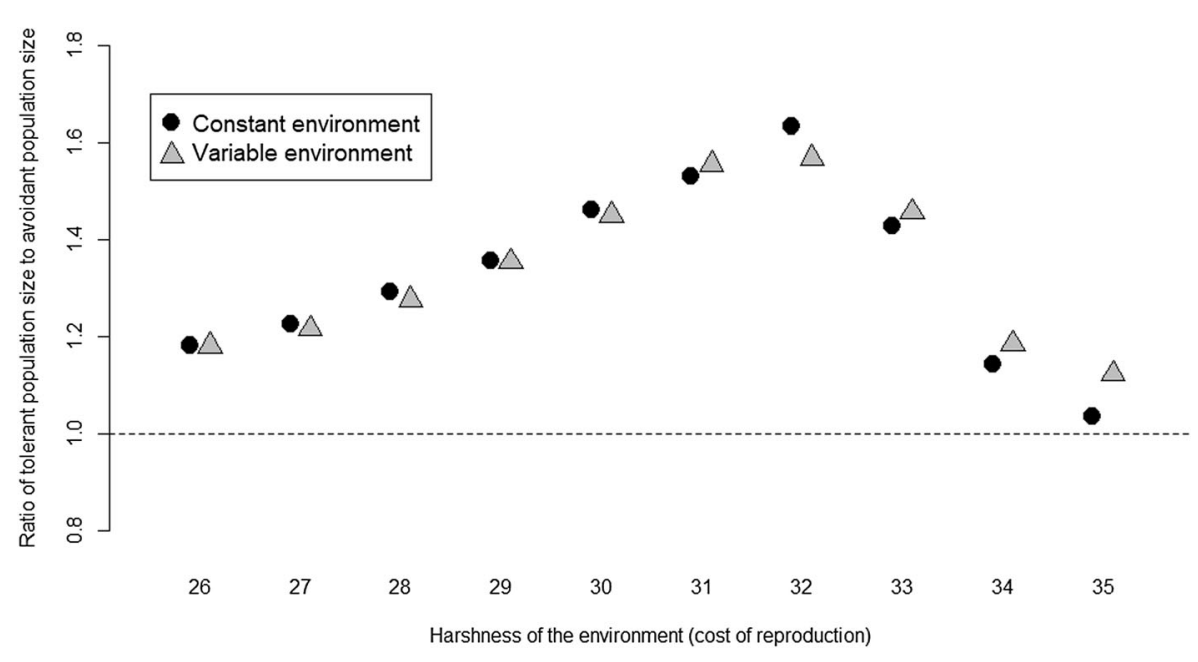

Fig. 7 Interaction between tolerance and cost of reproduction for a constant environment (black circles) and variable environment (grey triangles). Each point is the mean tolerant population size/mean avoidant population size (dashed horizontal line indicates equal population sizes for tolerant and avoidant strategies). There were 200 realisations of each strategy for each level of cost of reproduction for both constant and variable environments. All realisations below cost of reproduction 32 persisted. Simulations where the population died out were discarded (see Fig. 5)

peak for the benefit of food sharing at harshness of 32, but that the drop from there as conditions become harsher is larger in a constant environment than a variable one. Tolerance is even more beneficial to overall population success in a harsh (over level 33) and variable environment than when environments are more productive and stable. However, this pattern is much less pronounced than the overall effect within harsh rather than benign environments.

\section{Discussion}

\section{The Relationship Between Ecology and Human Intergroup Tolerance}

The model outlined here considers the implications of tolerant or avoidant strategies on forager success and survival when encountering other groups under different environmental conditions.

Our simulations demonstrate that intergroup tolerance, allowing the exchange or sharing of resources between groups, has a significant effect on population survival in 'harsh' or difficult environments. Populations which share resources are likely to be more successful (i.e. increase in population) and are more likely to survive harsh environments where extinctions occur than those populations which do not share across borders. This finding supports arguments made on the basis of ethnographically documented resource transfers at times of famine (see for example Wiessner 2002).

We also demonstrate novel patterns within the broader advantages of tolerance. Firstly, the effects of intergroup tolerance are most significant in moderately harsh environments. In the harshest environments, population density becomes too low to support interactions (the cost of interactions are high compared to the resources needed 
to survive, groups have little resources to spare to share and survival becomes critical). In the most benign environments, however, the benefits of sharing become marginal (as resources for reproduction and survival are not threatened). Secondly, overall harshness has a far greater effect on the selection pressures promoting social tolerance than ecological variability, though ecological variability does have some effect.

The most significant finding in terms of broader debates over changes between 300,000 and 30,000 BP is that tolerance towards other groups and intergroup collaboration becomes advantageous as environments become harsher (though in extremely harsh environments it becomes difficult to maintain the level of intergroup contact required to make collaboration possible) and tolerance also becomes more advantageous as environments become more variable. Although to date there has been some understanding of why intergroup collaboration might make communities more resilient, there has been little understanding of the ecological factors which might influence this, or the limitations of collaborative strategies in certain ecological contexts. This finding therefore provides some support for suggestions that environmental variability may have played a role in social changes in recent human evolution (Potts 2013; Potts et al. 2018). However, the effects of environmental variability on the selective advantages of intergroup tolerance are much less pronounced than the overall effect within harsh rather than benign environments. This result is perhaps surprising given the emphasis in the literature on environmental variability as a driver for human evolutionary changes rather than environmental harshness per se. Whilst variability is clearly an influence on selective pressures, the potentially elevated significance of environmental harshness on intergroup interaction provides an important avenue for further research.

\section{Implications}

The simulations provide useful insights which may further our understanding of the archaeological record documenting key human transformations taking place 300,000 to 30,000 years ago.

Archaic humans in this period were uniquely pre-adapted to benefit from increasing social tolerance through their capacity to transfer resources to buffer shortfalls, as well as uniquely susceptible to ecological pressures due to their increasing reliance on many different resources (plant and animals resources for food, plant resources for medicines, raw materials (such as flint) for tool production). Simulation modelling explains why specific ecological conditions occurring in certain contexts in Africa after 300,000 years ago, a time of increasing aridification and increasingly variable environments, may have provided the conditions in which elevated selection pressures on intergroup social tolerance might have emerged, leading to the passing of a threshold point beyond which intergroup collaboration became a normal stable state.

Particularly elevated selection pressures would have characterised certain African populations due to a unique combination of body form, ecological context and geography. Gracile or more slightly built humans (i.e. emerging modern humans in contrast to more heavily built or 'robust' archaic species) have lower energy requirements, and when living in equatorial contexts with high productivity, would exist at higher population densities than robust forms. For this reason, early modern human African populations in many regions would have been buffered from low population densities at which intergroup interactions become impossible. Moreover, such populations 
would have been uniquely situated within a geographical situation in which large regional scale connectivity was possible. Increased friendly interactions and collaboration between groups would also have enhanced the spread of innovations, regardless of population size or density, thus further enabling greater adaptability to change.

The model also explains why anatomical features of 'self-domestication' associated with increasing tolerance are visible in African population after 300,000 years ago. Self-domestication represents an extreme form of social tolerance, affecting physiology, anatomy and behaviour, most probably through the action of changes in neural crest cells and their effect on the hypothalamic-pituitary-adrenal (HPA) axis (Wilkins et al. 2014). Whether the term 'self-domestication' is appropriate within human evolution or not (Sánchez-Villagra and van Schaik 2019; Shilton et al. 2020), both selective pressures on increased social tolerance and associated anatomical changes provide an explanation for the similarities seen in cranial and facial forms of ACMH compared to archaic species, to changes seen between domestic dogs and wolves (Fig. 8). Whereas domestication occurs through human influence within artificially 'domesticated' species, ecological conditions are an influencing factor where increasing levels of intergroup tolerance emerge in 'wild' contexts (Pisor and Surbeck 2019) (as described by Hare et al. 2012 for bonobos). Although explanations for this process in humans have to date largely drawn on internal social process (Hare 2017; Wrangham 2014, 2019), we argue here that ecological context will have had an important role to play in changing social tolerance and 'self-domestication' in humans.

Increased intergroup tolerance thus provides an alternative explanation to that of population size or density (Shennan 2001; Langley et al. 2008) for transformations in the occurrence of innovation and cumulative evolution during this period. However, it complements models that link these transformations to increases in population

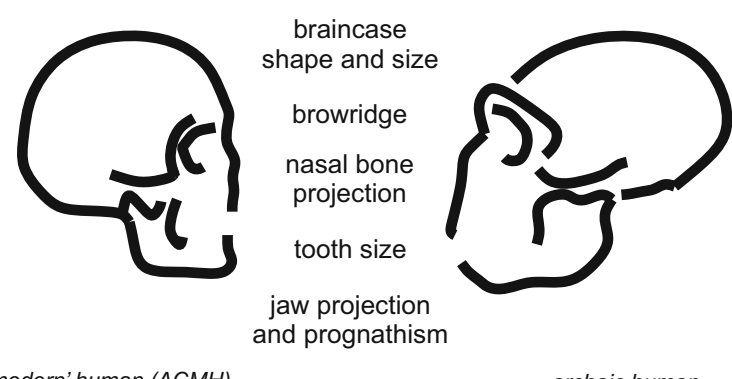

'modern' human $(\mathrm{ACMH})$

archaic human

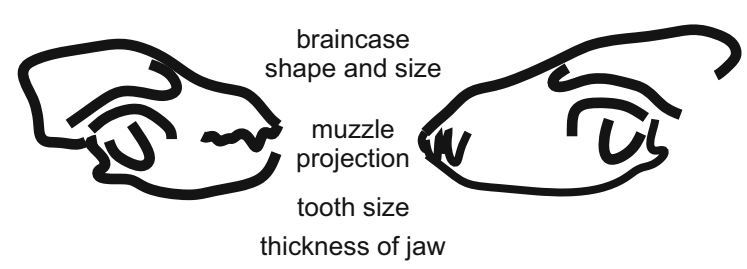

domestic dog wolf

Fig. 8 Similarities in cranio-facial changes seen between modern and archaic humans and between dogs and wolves (re-drawn after Theofanopoulou et al. 2017) 
connectivity (e.g. Powell et al. 2009), and, as demonstrated by our model, increased intergroup tolerance, can also lead to population increase. Moreover, explanations for 'modern human behaviour' based on changes brought about through increased intergroup tolerance do not depend on the questionable concept of an increasingly sophisticated cognition (e.g. Klein 2000).

\section{Limitations}

Simulation models allow us to test the implications of different scenarios and the relationships between many different variables. Our ABM allows an exploration of how particular processes (human intergroup behaviours) may have been affected by changes in certain variables (ecological changes). Like every model, this simulation cannot represent the full extent of all social interactions among archaic humans. It therefore simplifies some of these aspects to allow us to explore how different strategies of avoidance of other groups or tolerance with the potential for sharing are affected by ecological context.

There is clearly far more to the emergence of hunter-gatherer intergroup tolerance and sharing than emotional dispositions, even though they play an important role (Spikins 2019). For this reason, any model provides us with a starting point and not an end. For example, the level of ecological variability we modelled played only a minor role in influencing the advantages or disadvantages of sharing. However, this may be limited by modelling only 'simple' one step interactions, and not accommodating uniquely human emotions such as gratitude (which may play a key role in maintaining generalised reciprocity; Nowak and Roch 2007; Ma et al. 2017; Smith et al. 2017) nor cultural behaviours such as gift giving (Coward 2015). Future models might address such issues.

\section{Further Research}

The model described here is based at the level of the individual and considered the success of different strategies when compared against each other. This could be developed further in several ways. For example, it would be possible to add an evolutionary component (i.e. to enable individuals to evolve across successive generations). This additional complexity would allow questions about evolutionary mechanisms such as group selection to be addressed. Sharing of knowledge could be an additional element which would enable cultural evolution, potentially occurring differently within different groups (Powell et al. 2009, Vaesen et al. 2016, Lucchesi et al. 2020). Differences in memory capacities might also be incorporated into further models (see Cox et al.1999).

\section{Research Contribution Within Agent-Based Models in Archaeology}

As well as contributing to our understanding of changes taking place 300,000 to 30,000 years ago, particularly the factors influencing the proliferation of regional social networks and increased regional mobility, this research contributes broadly to existing agent-based models which have been used to better understand how resource characteristics influence foraging behaviours. Premo (2005) developed a preliminary model to 
consider the evolution of food sharing for example. Janssen and Hill (2014), for example, developed a model of foraging behaviour based on actualistic studies of the Hadza, and extended their model to demonstrate that as hunted resources become more clumped the movement distances of hunters reduced (Janssen and Hill 2016). Our model goes beyond resource acquisition and specifically focuses on the relatively under researched topic of food sharing between groups. Models considering intergroup behaviour in this way are rare, with the exception of Santos et al. (2015) who explore resource sharing strategies when groups encounter prolific resources in the form of whale carcasses.

\section{Conclusions}

We demonstrate here that external ecological factors may have been more significant in the process of increasing human social tolerance and population connectivity and, in turn, the emergence of 'modern human behaviour' than has previously been suggested.

As we have shown, archaic communities would have been particularly sensitive to the effects which ecological changes have on the relative advantages and disadvantages of intergroup social behaviour. They displayed some capacity to share resources between groups and depended on a variety of different resources. The capacity to be tolerant and interact with unfamiliar individuals would have been under particular selection pressures from $\sim 300,000$ years ago because of the relationship between archaic human resource requirements and ecological changes. Firstly, plant foods and animal resources needed not only for food but also to make tools or medicines are affected by ecological changes, and moreover groups may have depended on access to other essential resources, such as lithic raw materials found outside of their own home ranges. Secondly, ecological factors which influence availability of resources and resource access - including both overall harshness of environment and increasing variability and unpredictably_-would have influenced selection pressures on intergroup attitudes and behaviours.

Our model demonstrates that severe resource pressures as well as ecological variability, occurring in environments where population densities are sufficient to allow intergroup interaction, place particular selective pressures on intergroup social tolerance. As a result, particular conditions in Africa after 300,000 years ago may have pushed humans past a turning point in adaptive changes. Once physiological changes passed beyond a certain threshold point, intergroup collaboration may have become the stable state, leading to increasing dependence on varied resources and high levels of social connection, in turn laying the basis for social and cultural transformations.

The effect of ecological changes on intergroup dispositions provides us with an important alternative explanation for changes in social behaviour in recent human evolution. Whilst there has been some understanding of the significance of intergroup collaboration in resilience to ecological changes, this model adds an understanding of how and why intergroup collaboration may have emerged. This approach moves beyond concepts of the progressive development of 'modern' cognition towards a more complex relationship between mind, body and social relationships, and moreover provides a means of linking theoretical approaches to ecology and anatomical changes with approaches to social-cognitive changes. Furthermore, by focusing on how 
ecological context can influence physiological and behavioural changes, we hope to move towards an understanding of social transformations as part of different evolutionary branches and possibilities, rather than a ladder of progression.

Supplementary Information The online version contains supplementary material available at https://doi.org/ 10.1007/s10816-020-09503-5.

Funding We acknowledge the support of the YCCSA (York Cross-disciplinary Centre for Systems Analysis) Internship Programme for the support for Seren John-Wood (summer internship 2019, no grant number), the John Templeton Foundation Figuring the Roots of Gratitude Project (grant reference 61389) for the support for part of Penny Spikins time and the Hunt Postdoctoral Fellowship from the Wenner Gren Foundation (grant number: 9862) for support for Jennifer C. French.

\section{Compliance with Ethical Standards}

Conflict of Interest The authors declare that they have no conflicts of interest.

Open Access This article is licensed under a Creative Commons Attribution 4.0 International License, which permits use, sharing, adaptation, distribution and reproduction in any medium or format, as long as you give appropriate credit to the original author(s) and the source, provide a link to the Creative Commons licence, and indicate if changes were made. The images or other third party material in this article are included in the article's Creative Commons licence, unless indicated otherwise in a credit line to the material. If material is not included in the article's Creative Commons licence and your intended use is not permitted by statutory regulation or exceeds the permitted use, you will need to obtain permission directly from the copyright holder. To view a copy of this licence, visit http://creativecommons.org/licenses/by/4.0/.

\section{References}

Agam, A., \& Barkai, R. (2016). Not the brain alone: the nutritional potential of elephant heads in Paleolithic sites. Quaternary International, 406(B), 218-226.

Ames, C. J. H., Riel-Salvatore, J., \& Collins, B. R. (2013). Why we need an alternative approach to the study of modern human behaviour. Canadian Journal of Archaeology / Journal Canadien d'Archéologie, $37(1), 21-47$.

Bird, D. W., Bird, R. B., Codding, B. F., \& Zeanah, D. W. (2019). Variability in the organization and size of hunter-gatherer groups: foragers do not live in small-scale societies. Journal of Human Evolution, 131, 96-108.

Brantingham, P. J. (2003). A neutral model of stone raw material procurement. American Antiquity, 68(3), 487-509.

Brooks, A. S., Yellen, J. E., Potts, R., Behrensmeyer, A. K., Deino, A. L., Leslie, D. E., Ambrose, S. H., Ferguson, J. R., d’Errico, F., Zipkin, A. M., Whittaker, S., Post, J., Veatch, E. G., Foecke, K., \& Clark, J. B. (2018). Long-distance stone transport and pigment use in the earliest middle stone age. Science, 360(6384), 90-94.

Castellano, S., Parra, G., Sánchez-Quinto, F. A., Racimo, F., Kuhlwilm, M., Kircher, M., et al. (2014). Patterns of coding variation in the complete exomes of three Neandertals. Proceedings of the National Academy of Sciences USA, 111(18), 6666-6671.

Cegielski, W. H., \& Rogers, J. D. (2016). Rethinking the role of agent-based modeling in archaeology. Journal of Anthropological Archaeology, 41, 283-298.

Cieri, R. L., Churchill, S. E., Franciscus, R. G., Tan, J., \& Hare, B. (2014). Craniofacial feminization, social tolerance, and the origins of behavioral modernity. Current Anthropology, 55(4), 419-443.

Coward, F. (2015). Scaling up: material culture as scaffold for the social brain. Quaternary International, 405(A), 78-90. 
Cox, S. J., Slockin, T. J., \& Steele, J. (1999). Group size, memory, and interaction rate in the evolution of cooperation. Current Anthropology, 40(3), 369-376.

Decety, J., Norman, G. J., Berntson, G. G., \& Cacioppo, J. T. (2012). A neurobehavioral evolutionary perspective on the mechanisms underlying empathy. Progress in Neurobiology, 98(1), 38-48.

d'Errico, F., \& Banks, W. E. (2013). Identifying mechanisms behind Middle Paleolithic and Middle Stone Age cultural trajectories. Current Anthropology, 54(S8), S371-S387.

Djindjian, F. (2012). Is the MP-EUP transition also an economic and social revolution? Quaternary International, 259, 72-77.

Domínguez-Rodrigo, M., Bunn, H. T., Mabulla, A. Z. P., Baquedano, E., Uribelarrea, D., Pérez-González, A., et al. (2014). On meat eating and human evolution: a taphonomic analysis of BK4b (Upper Bed II, Olduvai Gorge, Tanzania), and its bearing on hominin megafaunal consumption. Quaternary International, 322-323, 129-152.

Dyble, M., Thompson, J., Smith, D., Salali, G. D., Chaudhary, N., Page, A. E., Vinicuis, L., Mace, R., \& Migliano, A. B. (2016). Networks of food sharing reveal the functional significance of multilevel sociality in two hunter-gatherer groups. Current Biology, 15, 2017-2021.

Ekshtain, R., Malinsky-Buller, A., Ilani, S., Segal, I., \& Hovers, E. (2014). Raw material exploitation around the Middle Paleolithic site of 'Ein Qashish. Quaternary International, 331, 248-266.

Ekshtain, R., Ilani, S., Segal, I., \& Hovers, E. (2017). Local and nonlocal procurement of raw material in Amud Cave, Israel: the complex mobility of Late Middle Paleolithic groups. Geoarchaeology, 32(2), 189-214.

Faurby, S., Silvestro, D., Werdelin, L., \& Antonelli, A. (2020). Brain expansion in early hominins predicts carnivore extinctions in East Africa. Ecology Letters, 23(3), 537-544.

Féblot-Augustins, J. (1999). Raw material transport patterns and settlement systems in the European Lower and Middle Palaeolithic: continuity, change and variability. In W. Roebroeks \& C. Gamble (Eds.), The Middle Palaeolithic occupation of Europe (pp. 193-214). Leiden: Leiden University Press.

Foley, R. A. (2018). Evolutionary geography and the afrotropical model of hominin evolution. Bulletins et Mémoires de la Société d'Anthropologie de Paris, 30(1-2), 17-31.

French, J. C. (2016). Demography and the Palaeolithic archaeological record. Journal of Archaeological Method and Theory, 23(1), 150-199.

French, J. C. (2018). The Palaeolithic archaeological record and the materiality of imagination: a response to J. Wentzel van Huyssteen. In A. Fuentes \& C. Deane-Drummond (Eds.), Evolution of wisdom: major and minor keys (pp. 57-63). Press Books: Center for Theology, Science, and Human Flourishing.

Galway-Witham, J., Cole, J., \& Stringer, C. (2019). Aspects of human physical and behavioural evolution during the last 1 million years. Journal of Quaternary Science, 34(6), 355-378.

Gamble, C. (2009). Human display and dispersal: a case study from biotidal Britain in the Middle and Upper Pleistocene. Evolutionary Anthropology, 18(4), 144-156.

Greenbaum, G., Friesem, D. E., Hovers, E., Feldman, M. W., \& Kolodny, O. (2019). Was inter-population connectivity of Neanderthals and modern humans the driver of the Upper Paleolithic transition rather than its product? Quaternary Science Reviews, 217, 316-329.

Grove, M., Pearce, E., \& Dunbar, R. I. M. (2012). Fission-fusion and the evolution of hominin social systems. Journal of Human Evolution, 62(2), 191-200.

Gurven, M., \& Kaplan, H. (2007). Longevity among hunter-gatherers: a cross-cultural examination. Population and Development Review, 33(2), 321-365.

Hardy, K. (2018). Plant use in the Lower and Middle Palaeolithic: food, medicine and raw materials. Quaternary Science Reviews, 191, 393-405.

Hare, B. (2017). Survival of the friendliest: Homo sapiens evolved via selection for prosociality. Annual Review of Psychology, 68(1), 155-186.

Hare, B., Wobber, V., \& Wrangham, R. (2012). The self-domestication hypothesis: evolution of bonobo psychology is due to selection against aggression. Animal Behaviour, 83(3), 573-585.

Hare, B., \& Yamamoto, S. (2017). Bonobos: unique in mind, brain and behavior. Oxford: Oxford University Press.

Henshilwood, C. S., \& Marean, C. W. (2003). The origin of modern human behavior. Current Anthropology, 44(5), 627-651.

Hill, K., Hurtado, A. M., \& Walker, R. S. (2007). High adult mortality among Hiwi hunter-gatherers: implications for human evolution. Journal of Human Evolution, 52(4), 443-454.

Hill, K. R., Wood, B. M., Baggio, J., Hurtado, A. M., \& Boyd, R. T. (2014). Hunter-gatherer inter-band interaction rates: implications for cumulative culture. PLoS One, 9(7), e102806.

Hoffmann, D. L., Standish, C. D., García-Diez, M., Pettitt, P. B., Milton, J. A., Zilhão, J., Alcolea-González, J. J., Cantalejo-Duarte, P., Collado, H., de Balbín, R., Lorblanchet, M., Ramos-Muñoz, J., Weniger, G. C., 
\& Pike, A. W. G. (2018). U-Th dating of carbonate crusts reveals Neandertal origin of Iberian cave art. Science, 359(6378), 912-915.

Hovers, E. (2018). Continuity and change in research about the Neanderthals in the Levant. Neanderthal: The Conference, Gibraltar Museum, 13th, (September 2018).

Hublin, J.-J., Ben-Ncer, A., Bailey, S. E., Freidline, S. E., Neubauer, S., Skinner, M. M., Bergmann, I., Le Cabec, A., Benazzi, S., Harvati, K., \& Gunz, P. (2017). New fossils from Jebel Irhoud, Morocco and the pan-African origin of Homo sapiens. Nature, 546(7657), 289-292.

Janssen, M. A., \& Hill, K. (2014). Benefits of grouping and cooperative hunting among Ache huntergatherers: insights from an agent-based foraging model. Human Ecology, 42(6), 823-835.

Janssen, M. A., \& Hill, K. (2016). An agent-based model of resource distribution on hunter-gatherer foraging strategies: clumped habitats favor lower mobility but result in higher foraging returns. in J. A., Barceló, \& F. Del Castillo, (Eds.). (2016). Simulating Prehistoric and Ancient Worlds (pp. 159-174): Dordrecht: Springer.

Joordens, J. C. A., d'Errico, F., Wesselingh, F. P., Munro, S., de Vos, J., Wallinga, J., Ankjærgaard, C., Reimann, T., Wijbrans, J. R., Kuiper, K. F., Mücher, H. J., Coqueugniot, H., Prié, V., Joosten, I., van Os, B., Schulp, A. S., Panuel, M., van der Haas, V., Lustenhouwer, W., Reijmer, J. J. G., \& Roebroeks, W. (2015). Homo erectus at Trinil on Java used shells for tool production and engraving. Nature, 518(7538), 228-231.

Kelly, R. L. (2013). The lifeways of hunter-gatherers: the foraging spectrum. Cambridge: Cambridge University Press.

Kissel, M., \& Fuentes, A. (2018). "Behavioral modernity" as a process, not an event, in the human niche. Time and Mind, 11(2), 163-183.

Klein, R. G. (2000). Archeology and the evolution of human behavior. Evolutionary Anthropology, 9(1), 1736.

Klein, R. G. (2019). Population structure and the evolution of Homo sapiens in Africa. Evolutionary Anthropology, 28(4), 179-188.

Křivan, V., \& Eisner, J. (2003). Optimal foraging and predator-prey dynamics III. Theoretical Population Biology, 63(4), 269-279.

Kutzbach, J. E., Guan, J., He, F., Cohen, A. S., Orland, I. J., \& Chen, G. (2020). African climate response to orbital and glacial forcing in 140,000-y simulation with implications for early modern human environments. Proceedings of the National Academy of Sciences of the United States of America, 117(5), 22552264.

Lalueza-Fox, C., Rosas, A., Estalrrich, A., Gigli, E., Campos, P. F., García-Tabernero, A., García-Vargas, S., Sánchez-Quinto, F., Ramírez, O., Civit, S., Bastir, M., Huguet, R., Santamaría, D., Gilbert, M. T. P., Willerslev, E., \& de la Rasilla, M. (2011). Genetic evidence for patrilocal mating behavior among Neandertal groups. Proceedings of the National Academy of Sciences USA, 108(1), 250-253.

Lamb, H. F., Bates, C. R., Bryant, C. L., Davies, S. J., Huws, D. G., Marshall, M. H., Roberts, H. M., \& Toland, H. (2018). 150,000-year palaeoclimate record from northern Ethiopia supports early, multiple dispersals of modern humans from Africa. Scientific Reports, 8(1), 1077.

Langley, M. C., Clarkson, C., \& Ulm, S. (2008). Behavioural complexity in Eurasian Neanderthal populations: a chronological examination of the archaeological evidence. Cambridge Archaeological Journal, 18(3), 289-307.

Lavi, N., \& Friesem, D. E. (2019). Towards a broader view of hunter-gatherer sharing. Cambridge: MacDonald Institute Monographs.

Layton, R., O’Hara, S., \& Bilsborough, A. (2012). Antiquity and social functions of multilevel social organization among human hunter-gatherers. International Journal of Primatology, 33(5), 1215-1245.

Lucchesi, S., Cheng, L., Janmaat, K., Mundry, R., Pisor, A., \& Surbeck, M. (2020). Beyond the group: how food, mates, and group size influence intergroup encounters in wild bonobos. Behavioral ecology: official journal of the International Society for Behavioral Ecology, 31(2), 519-532.

Ma, L. K., Tunney, R. J., \& Ferguson, E. (2017). Does gratitude enhance prosociality? A meta-analytic review. Psychological Bulletin, 143(6), 601-635.

Marsh, A. A. (2019). The caring continuum: evolved hormonal and proximal mechanisms explain prosocial and antisocial extremes. Annual Review of Psychology, 70(1), 347-371.

Marwick, B. (2003). Pleistocene exchange networks as evidence for the evolution of language. Cambridge Archaeological Journal, 13(01), 67-81.

Mellars, P. (2007). Rethinking the human revolution: Eurasian and African perspectives. In P. Mellars, K. Boyle, O. Bar Yosef, \& C. Stringer (Eds.), Rethinking the human revolution (pp. 1-14). Cambridge: McDonald Institute Monographs. 
Moncel, M.-H., \& Schreve, D. (2016). The Acheulean in Europe: origins, evolution and dispersal. Quaternary International, 411, 1-8.

Nash, D. J., Coulson, S., Staurset, S., Ullyott, J. S., Babutsi, M., Hopkinson, L., \& Smith, M. P. (2013). Provenancing of silcrete raw materials indicates long-distance transport to Tsodilo Hills, Botswana, during the Middle Stone Age. Journal of Human Evolution, 64(4), 280-288.

Nash, D. J., Coulson, S., Staurset, S., Ullyott, J. S., Babutsi, M., \& Smith, M. P. (2016). Going the distance: mapping mobility in the Kalahari Desert during the Middle Stone Age through multi-site geochemical provenancing of silcrete artefacts. Journal of Human Evolution, 96, 113-133.

Nowak, M. A., \& Roch, S. (2007). Upstream reciprocity and the evolution of gratitude. Proceedings of the Royal Society B, 274(1610), 605-609.

Owen, R. B. Muiruri, V. M; Lowenstein, T. K; Renaut, R. W; Rabideaux, N; Luo, S., Deino, A. L. Sier, M. J., Dupont-Nivet, G., McNulty, E. P., Leet, K., Cohen, A., Campisano, C., Deocampo, D., Shen, C.-C., Billingsley, ; Mbuthia, A. (2018) Progressive aridification in East Africa over the last half million years and implications for human evolution, Proceedings of the National Academy of Sciences of the United States of America 115(44), pp. 11174-11179.

Petraglia, M. D., Breeze, P. S., \& Groucutt, H. S. (2019). Blue Arabia, Green Arabia: examining human colonisation and dispersal models. In N. M. A. Rasul \& I. C. F. Stewart (Eds.), Geological setting, palaeoenvironment and archaeology of the Red Sea (pp. 675-683). Dordrecht: Springer.

Pisor, A. C., \& Surbeck, M. (2019). The evolution of intergroup tolerance in nonhuman primates and humans. Evolutionary Anthropology, 28(4), 210-233.

Potts, R. (2013). Hominin evolution in settings of strong environmental variability. Quaternary Science Reviews, 73, 1-13.

Potts, R., Behrensmeyer, A. K., Faith, J. T., Tryon, C. A., Brooks, A. S., Yellen, J. E., Deino, A. L., Kinyanjui, R., Clark, J. B., Haradon, C. M., Levin, N. E., Meijer, H. J. M., Veatch, E. G., Owen, R. B., \& Renaut, R. W. (2018). Environmental dynamics during the onset of the Middle Stone Age in eastern Africa. Science, 360(6384), 86-90.

Powell, A., Shennan, S., \& Thomas, M. G. (2009). Late Pleistocene demography and the appearance of modern human behavior. Science, 324(5932), 1298-1301.

Premo, L. S. (2005). Patchiness and prosociality: an agent-based model of Plio/Pleistocene hominid food sharing. In P. Davidsson, B. Logan, \& K. Takadama (Eds.), Multi-agent and multi-agent-based simulation. MABS 2004 (pp. 210-224). Lecture Notes in Computer Science (vol. 3415). Berlin, Heidelberg: Springer.

Premo, L. S. (2006). Exploratory agent-based models: towards an experimental ethnoarchaeology, Digital discovery: exploring new frontiers in human heritage. Computer Applications in Archaeology, 2006, 2936.

Prüfer, K., Racimo, F., Patterson, N., Jay, F., Sankararaman, S., Sawyer, S., Heinze, A., Renaud, G., Sudmant, P. H., de Filippo, C., Li, H., Mallick, S., Dannemann, M., Fu, Q., Kircher, M., Kuhlwilm, M., Lachmann, M., Meyer, M., Ongyerth, M., Siebauer, M., Theunert, C., Tandon, A., Moorjani, P., Pickrell, J., Mullikin, J. C., Vohr, S. H., Green, R. E., Hellmann, I., Johnson, P. L. F., Blanche, H., Cann, H., Kitzman, J. O., Shendure, J., Eichler, E. E., Lein, E. S., Bakken, T. E., Golovanova, L. V., Doronichev, V. B., Shunkov, M. V., Derevianko, A. P., Viola, B., Slatkin, M., Reich, D., Kelso, J., \& Pääbo, S. (2014). The complete genome sequence of a Neanderthal from the Altai Mountains. Nature, 505(7481), 43-49.

Railsback, S. F., \& Grimm, V. (2019). Agent-based and individual-based modeling: a practical introduction (2nd ed.). Princeton: Princeton University Press.

Richter, D., Grün, R., Joannes-Boyau, R., Steele, T. E., Amani, F., Rué, M., Fernandes, P., Raynal, J. P., Geraads, D., Ben-Ncer, A., Hublin, J. J., \& McPherron, S. P. (2017). The age of the hominin fossils from Jebel Irhoud, Morocco, and the origins of the Middle Stone Age. Nature, 546(7657), 293-296.

Ríos, L., Rosas, A., Estalrrich, A., García-Tabernero, A., Bastir, M., Huguet, R., Pastor, F., Sanchís-Gimeno, J. A., \& de la Rasilla, M. (2015). Possible further evidence of low genetic diversity in the El Sidrón (Asturias, Spain) Neandertal group: congenital clefts of the atlas. PLoS One, 10(9), e0136550.

Ríos, L., Kivell, T. L., Lalueza-Fox, C., Estalrrich, A., García-Tabernero, A., Huguet, R., Quintino, Y., de la Rasilla, M., \& Rosas, A. (2019). Skeletal anomalies in the Neandertal family of El Sidrón (Spain) support a role of inbreeding in Neandertal extinction. Scientific Reports, 9(1), 1697.

Rito, T., Vieira, D., Silva, M., Conde-Sousa, E., Pereira, L., Mellars, P., Richards, M. B., \& Soares, P. (2019). A dispersal of Homo sapiens from southern to eastern Africa immediately preceded the out-of-Africa migration. Scientific Reports, 9, (1), 4728.

Robinson, E. J. H., \& Barker, J. L. (2017). Inter-group cooperation in humans and other animals. Biology Letters, 13(3), 20160793. 
Romanowska, I., Crabtree, S. A., Harris, K., \& Davies, B. (2019). Agent-based modeling for archaeologists: Part 1 of 3. Advances in Archaeological Practice, 7(2), 178-184.

Sánchez-Villagra, M. R., \& van Schaik, C. P. (2019). Evaluating the self-domestication hypothesis of human evolution. Evolutionary Anthropology, 28(3), 133-143.

Santos, J. I., Pereda, M., Zurro, D., Álvarez, M., Caro, J., Galán, J. M., \& Briz i Godino, I. (2015). Effect of resource spatial correlation and hunter-fisher-gatherer mobility on social cooperation in Tierra del Fuego. PLoS One, 10(4), e0121888.

Sapolsky, R. M. (2017). Behave: the biology of humans at our best and worstPenguin.

Scerri, E. M. L., Thomas, M. G., Manica, A., Gunz, P., Stock, J. T., \& Stringer, C. (2018). Did our species evolve in subdivided populations across Africa, and why does it matter? Trends in Ecology \& Evolution, 33(8), 582-594.

Shennan, S. (2001). Demography and cultural innovation: a model and its implications for the emergence of modern human culture. Cambridge Archaeological Journal, 11(1), 5-(1), 5-16.

Shilton, D., Breski, M., Dor, D., \& Jablonka, E. (2020). Human social evolution: self-domestication or selfcontrol? Frontiers in Psychology, 11, 134.

Sikora, M., Seguin-Orlando, A., Sousa, V. C., Albrechtsen, A., Korneliussen, T., Ko, A., Rasmussen, S., Dupanloup, I., Nigst, P. R., Bosch, M. D., Renaud, G., Allentoft, M. E., Margaryan, A., Vasilyev, S. V., Veselovskaya, E. V., Borutskaya, S. B., Deviese, T., Comeskey, D., Higham, T., Manica, A., Foley, R., Meltzer, D. J., Nielsen, R., Excoffier, L., Mirazon Lahr, M., Orlando, L., \& Willerslev, E. (2017). Ancient genomes show social and reproductive behavior of early Upper Paleolithic foragers. Science, 358(6363), 659-662.

Simon, M. H., Ziegler, M., Bosmans, J., Barker, S., Reason, C. J. C., \& Hall, I. R. (2015). Eastern South African hydroclimate over the past 270,000 years. Scientific Reports, 5(1), 18153.

Smith, A., Pedersen, E. J., Forster, D. E., McCullough, M. E., \& Lieberman, D. (2017). Cooperation: the roles of interpersonal value and gratitude. Evolution and Human Behavior, 38(6), 695-703.

Spikins, P. (2019). Sharing and inclusion: a socio-emotional model of generosity, trust and response to vulnerability in the distant past. In N. Levi \& D. Friesem (Eds.), Towards a broader view of huntergatherer sharing (pp. 57-66). Cambridge: MacDonald Institute Monographs.

Spikins, P. (2021). Hidden depths: the palaeolithic origins of our most human emotions. White Rose University Press.

Spikins, P., Needham, A., Wright, B., Dytham, C., Gatta, M., \& Hitchens, G. (2019). Living to fight another day: the ecological and evolutionary significance of Neanderthal healthcare. Quaternary Science Reviews, $217,98-118$.

Spinapolice, E. E. (2012). Raw material economy in Salento (Apulia, Italy): new perspectives on Neanderthal mobility patterns. Journal of Archaeological Science, 39(3), 680-689.

Stringer, C., \& Galway-Witham, J. (2017). Palaeoanthropology. On the origin of our species Nature, $546(7657), 212-214$.

Tan, J., \& Hare, B. (2013). Bonobos share with strangers. PLoS One, 8(1), e51922.

Tan, J., Ariely, D., \& Hare, B. (2017). Bonobos respond prosocially toward members of other groups. Scientific Reports, 7(1), 14733.

Theofanopoulou, C., Andirko, A., \& Boeckx, C. (2018). Oxytocin and vasopressin receptor variants as a window onto the evolution of human prosociality. In bioRxiv (p. 460584). https://doi.org/10.1101/ 460584.

Theofanopoulou, C., Gastaldon, S., O’Rourke, T., Samuels, B. D., Martins, P. T., Delogu, F., Alamri, S., \& Boeckx, C. (2017). Self-domestication in Homo sapiens: insights from comparative genomics. PLoS One, 12, (10), e0185306.

Thomas, J., \& Kirby, S. (2018). Self domestication and the evolution of language. Biology and Philosophy, 33(9), 9. https://doi.org/10.1007/s10539-018-9612-8.

Thornton, A., \& McAuliffe, K. (2006). Teaching in wild meerkats. Science, 313(5784), 227-229.

Timmermann, A., \& Friedrich, T. (2016). Late Pleistocene climate drivers of early human migration. Nature, 538(7623), 92-95.

Trinkaus, E. (2018). An abundance of developmental anomalies and abnormalities in Pleistocene people. Proceedings of the National Academy of Sciences USA, 115(47), 11941-11946.

Vaesen, K., Collard, M., Cosgrove, R., \& Roebroeks, W. (2016). Population size does not explain past changes in cultural complexity. Proceedings of the National Academy of Sciences USA, 113(16), E2241E2247.

White, J. W., Rassweiler, A., Samhouri, J. F., Stier, A. C., \& White, C. (2014). Ecologists should not use statistical significance tests to interpret simulation model results. Oikos, 123(4), 385-388. 
Wiessner, P. (2002). Taking the risk out of risky transactions: a forager's dilemma. In F. K. Salter (Ed.), Risky transactions: trust, kinship, and ethnicity (pp. 21-43). Oxford: Berghan Books.

Wilkins, A. S., Wrangham, R. W., \& Tecumseh Fitch, W. (2014). The "Domestication Syndrome" in mammals: a unified explanation based on neural crest cell behavior and genetics. Genetics, 197(3), 795-808.

Wittig, R. M., Crockford, C., Deschner, T., Langergraber, K. E., Ziegler, T. E., \& Zuberbühler, K. (2014). Food sharing is linked to urinary oxytocin levels and bonding in related and unrelated wild chimpanzees. Proceedings of the Royal Society B, 281(1778), 20133096.

Wrangham, R. (2014). Did Homo sapiens self-domesticate? https:/carta.anthropogeny.org/events/sessions/ did-homo-sapiens-self-domesticate.

Wrangham, R. W. (2019). Hypotheses for the evolution of reduced reactive aggression in the context of human self-domestication. Frontiers in Psychology, 10, 1914.

Zilhão, J., Angelucci, D. E., Badal-García, E., d'Errico, F., Daniel, F., Dayet, L., et al. (2010). Symbolic use of marine shells and mineral pigments by Iberian Neandertals. Proceedings of the National Academy of Sciences USA, 107(3), 1023-1028.

Publisher's Note Springer Nature remains neutral with regard to jurisdictional claims in published maps and institutional affiliations.

\section{Affiliations}

\section{Penny Spikins ${ }^{1} \cdot$ Jennifer C. French ${ }^{2} \cdot$ Seren John-Wood ${ }^{3,4} \cdot$ Calvin Dytham $^{5}$}

1 Department of Archaeology, Archaeology PalaeoHub, University of York, York YO10 5DD, UK

2 Department of Archaeology, Classics, and Egyptology, University of Liverpool, Liverpool L69 7WZ, UK

3 York Cross-disciplinary Centre for Systems Analysis (YCCSA) Internship Programme, University of York, York, UK

4 University College London, London, UK

5 Department of Biology, University of York, York YO10 5DD, UK 